\title{
ASSESSING THE PHOTOGRAMMETRIC POTENTIAL OF CAMERAS IN PORTABLE DEVICES
}

\author{
M. J. Smith *, N. Kokkas \\ Faculty of Engineering, The University of Nottingham, \\ Nottingham Geospatial Building, Triumph Road, Nottingham NG7 2TU, UK \\ (martin.smith, nikolaos.kokkas)@ nottingham.ac.uk
}

Commission V, Working Group V/5

KEY WORDS: Camera, geometric, imagery, calibration, digital, modelling

\begin{abstract}
:
In recent years, there have been an increasing number of portable devices, tablets and Smartphone's employing high-resolution digital cameras to satisfy consumer demand. In most cases, these cameras are designed primarily for capturing visually pleasing images and the potential of using Smartphone and tablet cameras for metric applications remains uncertain. The compact nature of the host's devices leads to very small cameras and therefore smaller geometric characteristics. This also makes them extremely portable and with their integration into a multi-function device, which is part of the basic unit cost often makes them readily available.
\end{abstract}

Many application specialists may find them an attractive proposition where some modest photogrammetric capability would be useful. This paper investigates the geometric potential of these cameras for close range photogrammetric applications by:

- investigating their geometric characteristics using the self-calibration method of camera calibration and comparing results from a state-of-the-art Digital SLR camera.

- investigating their capability for 3D building modelling. Again, these results will be compared with findings from results obtained from a Digital SLR camera.

The early results presented show that the iPhone has greater potential for photogrammetric use than the iPad.

\section{INTRODUCTION}

\subsection{Background}

In recent years, there have been an increasing number of portable devices, tablets and Smartphone's employing highresolution digital cameras to satisfy consumer demand. In most cases, these cameras are designed primarily for capturing visually pleasing images, recording bar codes or some form of image coding. They are extremely mobile and convenient to carry and access as many people carry a phone or portable computer as part of everyday activities. The bulk and weight of digital single lens cameras has significantly reduced over the years as new plastics and materials in general have become stronger and lighter. However, they are still an additional item to carry around although the user does have significantly more control over the image captured. This is not just from the numerous manual settings that are available but they normally have the ability to accommodate interchangeable lens of different types and sizes. This flexibility and their high image quality normally make them the choice of the professional photographer or enthusiastic amateur.

Clearly, the convenience of cameras built into portable devices makes them attractive to many people and they are developing at an alarming rate. The Nokia 808 Pureview smart phone includes a 41-mpixel camera. It is not just about taking pictures or videos with these devices it is also the other integrated functionality that these devices possess such as instant, direct link with the internet, integrated GPS and accelerometers, etc. (Nokia808, 2012).

There are also many open source software packages for the amateur photogrammetrists to use with internet sites for building 3D models. This is now delivering 'photogrammetry', often without naming it, to the general public for interest and pleasure.

This leads us to the question, when will smart phones be of serious interest to the photogrammetrists? At the moment, the potential of using Smartphone and tablet cameras for metric applications remains uncertain.

The compact nature of the host devices leads to very small cameras and therefore small geometric characteristics. Of course, this is what makes them extremely portable and the integration into a multi function device often makes them readily available, as they are part of the basic unit cost. It also enables them to be an ideal tool for crowd sourcing of information which is becoming popular for 3D location modelling using open source software from 'holiday pictures'. The question the more serious photogrammetrist or surveyor would ask is 'how accurate are the models?' The answer starts with an examination of the imaging camera then an investigation in to the quality of 3D building models.

\footnotetext{
* Corresponding author.
} 
Many application specialists may find them an attractive proposition where some modest photogrammetric potential would be useful.

\subsection{Aims and objectives}

The overall aim of the research undertaken at The University of Nottingham is to investigate the photogrammetric potential of the cameras in portable devices. The aim of this paper is to present results from the initial stage of this research, which is investigating the camera geometric characteristics and the cameras potential for 3D building modelling. More specifically the following objectives have been investigated:

1. Using the self-calibration method of camera calibration an investigation will be undertaking into the geometric characteristics of cameras. The camera calibration results will be analysed, and compared with results from a stateof-the-art digital SLR camera.

2. Images will be used with close range photogrammetric processes for 3D building modelling. Again, these results will be compared with findings from results obtained from a state-of-the-art digital SLR camera.

\subsection{Methodology}

The methodology is based on understanding the camera systems, the three cameras to be used are the iPhone 4G, the iPad 2 and the Canon EOS 5D Mk II. The PhotoModeler software was used to undertake the following stages:

1. Camera calibration using a planar target field (as required by the software) to fulfil objective 1 . The comparison is undertaken by statistical differences and graphical representation of the radial lens distortion.

2. The creation of $3 \mathrm{D}$ building models by using the Nottingham Geospatial Building (NGB) as a test site to fulfil objective 2.The comparison of building models is undertaken by performing a 3D analysis between a reference building and the $3 \mathrm{D}$ models from the portable device cameras. The 3D comparison is performed using Geomagic Studio enabling the comprehensive assessment of any differences that exist between the two building models.

\section{TECHNOLOGY}

\subsection{The cameras and devices}

The cameras used in this project are shown in figure 1. The iPhone $4 \mathrm{G}$ is one of the latest range of phones which contain a digital camera. A summary of a few basic features are given in table 1 (iPhone 2012, iPad 2012, Canon 2012).

\begin{tabular}{|l|c|c|c|}
\hline \multicolumn{1}{|c|}{ Feature } & iPhone 4G & iPad 2 & $\begin{array}{c}\text { Canon EOS } \\
\text { 5D Mk II }\end{array}$ \\
\hline $\begin{array}{l}\text { No of pixels } \\
\text { (mpixels) }\end{array}$ & 5 & 0.6 & 21.1 \\
\hline $\begin{array}{l}\text { Nominal focal } \\
\text { length (mm) }\end{array}$ & 4.2 & 2.6 & 28 \\
\hline
\end{tabular}

Table 1. Camera characteristics

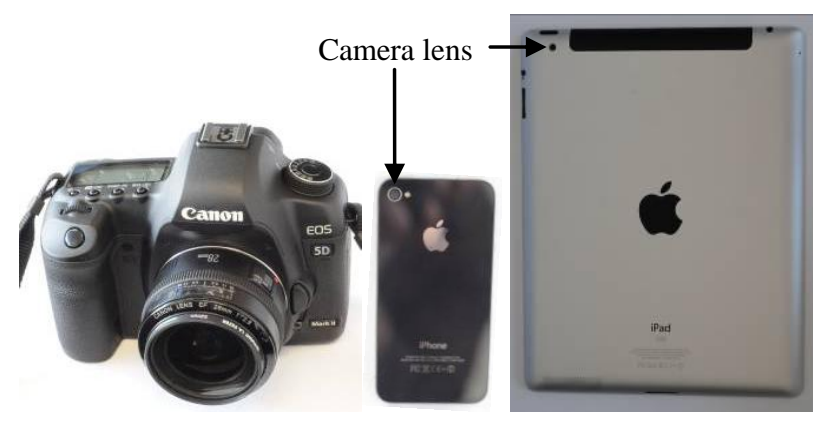

Figure 1. Images of the Canon EOS 5D Mk II, iPhone 4G and iPad 2 (left to right respectively)

\section{TRIALS, RESULTS AND ANALYSIS}

\subsection{Calibration frame results}

\subsubsection{Observations and computations}

The camera calibration was undertaken using a self-calibrating bundle block adjustment in PhotoModeler version 6 (PhotoModeler, 2012). PhotoModeler uses a camera calibration template shown in figure 2. This approach was used as the iPad and the iPhone does not allow a flash to be used to enable the use of the $3 \mathrm{D}$ calibration frame available at The University of Nottingham with coded retro reflective targets.

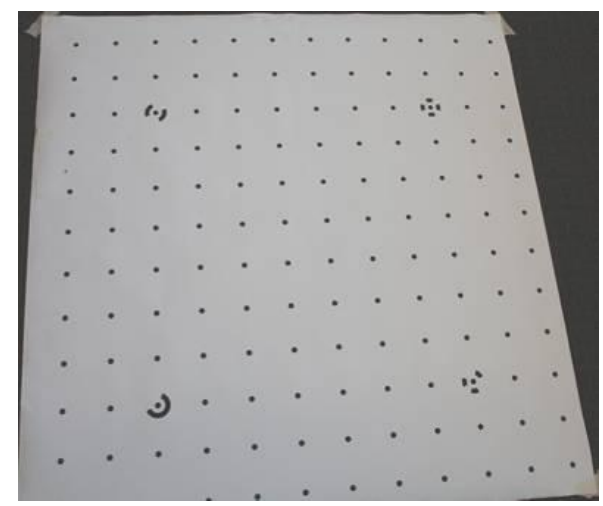

Figure 2. Calibration template used by PhotoModeler software

Camera self-calibration trials - iPhone 4G camera

Twelve photos captured from the iPhone $4 \mathrm{G}$ were used for the calibration process. The results are listed in table 2 .

\begin{tabular}{|l|l|l|}
\hline \multicolumn{1}{|c|}{ Parameter } & \multicolumn{1}{|c|}{ Value $\mathrm{mm}$} & \multicolumn{1}{c|}{$\begin{array}{c}\text { Standard } \\
\text { deviation } \mathrm{mm}\end{array}$} \\
\hline Focal Length & 4.198 & 0.010 \\
\hline Xp - principal point $\mathrm{x}$ & 2.195 & 0.001 \\
\hline Yp - principal point $\mathrm{y}$ & 1.632 & 0.004 \\
\hline $\mathrm{Fw}$ - CCD format width & 4.372 & 0.001 \\
\hline Fh - CCD format height & 3.265 & 0.001 \\
\hline K1 - radial distortion & 0.002078 & 0.00011 \\
\hline K2 - radial distortion & $0.000 \mathrm{e}+000$ & 0 \\
\hline K3 - radial distortion & $0.000 \mathrm{e}+000$ & 0 \\
\hline
\end{tabular}

Table 2. Self-calibration results for the iPhone $4 \mathrm{G}$ camera 
Pixel size $1.7 \mu \mathrm{m}$

Image measurement precision:

Overall RMS: 0.151 pixels

Maximum: 0.707 pixels

Minimum: $\quad 0.140$ pixels

Camera self-calibration trials - iPad 2 camera

Twelve 12 photos captured from the iPad 2 were used for the calibration process. The results are listed in table 3.

\begin{tabular}{|l|l|l|}
\hline \multicolumn{1}{|c|}{ Parameter } & \multicolumn{1}{|c|}{ Value $\mathrm{mm}$} & \multicolumn{1}{c|}{$\begin{array}{c}\text { Standard } \\
\text { deviation } \mathrm{mm}\end{array}$} \\
\hline Focal Length & 2.680 & 0.022 \\
\hline Xp - principal point $\mathrm{x}$ & 1.169 & 0.001 \\
\hline Yp - principal point y & 0.763 & 0.007 \\
\hline Fw - CCD format width & 2.286 & 0.005 \\
\hline Fh - CCD format height & 1.713 & 0.005 \\
\hline K1 - radial distortion & 0.001903 & 0.00047 \\
\hline K2 - radial distortion & -0.0005714 & 0.00015 \\
\hline K3 - radial distortion & $0.000 \mathrm{e}+000$ & 0 \\
\hline
\end{tabular}

Table 3. Self-calibration results for the iPad 2 camera

Pixel size $2.3 \mu \mathrm{m}$

Image measurement precision:

Overall RMS: 0.628 pixels

Maximum: 2.420 pixels

Minimum: $\quad 0.157$ pixels

Camera self-calibration trials - Canon EOS 5D Mk II

Twelve photos captured from the Canon EOS 5D Mk II were used for the calibration process. The results are listed in table 4 .

\begin{tabular}{|l|l|l|}
\hline \multicolumn{1}{|c|}{ Parameter } & \multicolumn{1}{|c|}{ Value $\mathrm{mm}$} & \multicolumn{1}{|c|}{$\begin{array}{c}\text { Standard } \\
\text { deviation } \\
\mathrm{mm}\end{array}$} \\
\hline Focal Length & 29.396 & 0.009 \\
\hline Xp - principal point $\mathrm{x}$ & 18.056 & 0.002 \\
\hline Yp - principal point y & 12.166 & 0.002 \\
\hline Fw - CCD format width & 36.497 & 0.001 \\
\hline Fh - CCD format height & 24.333 & 0.001 \\
\hline K1 - radial distortion & 0.0001259 & 0.00000033 \\
\hline K2 - radial distortion & -0.0000001535 & $8.8 \mathrm{e}-010$ \\
\hline K3 - radial distortion & $0.000 \mathrm{e}+000$ & 0 \\
\hline
\end{tabular}

Table 4. Self-calibration of Canon EOS 5D Mk II

Pixel size $6.5 \mu \mathrm{m}$

Image measurement precision:

Overall RMS: 0.102 pixels

Maximum: 0.496 pixels

Minimum: $\quad 0.082$ pixels

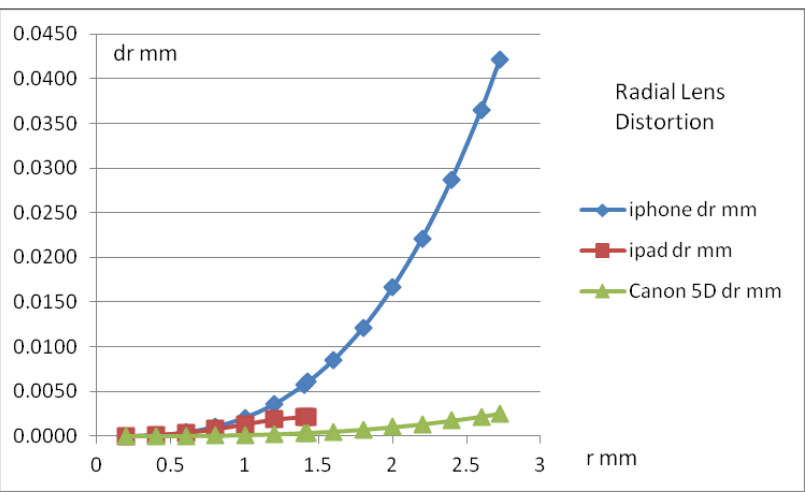

Figure 3. Radial lens distortion over the maximum radial distance of the iPhone

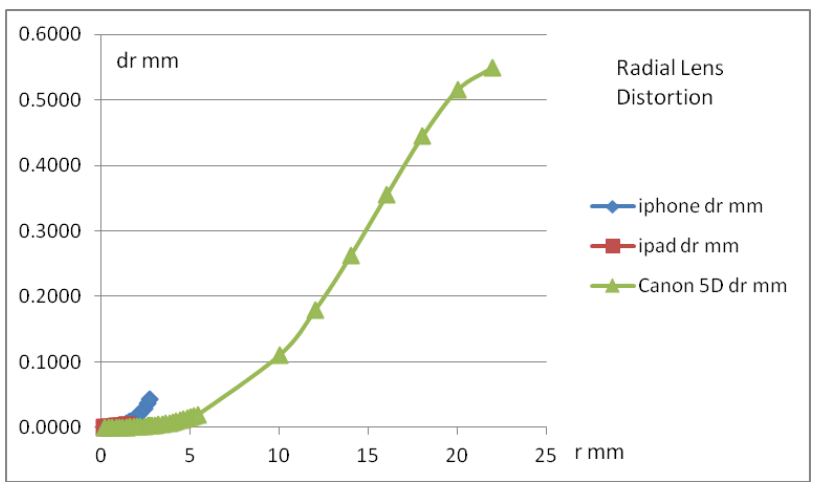

Figure 4. Radial lens distortion over the maximum radial distance of the Canon

\subsubsection{Camera calibration analysis of results}

Tables 2, 3 and 4 and the associated image measurement precisions form the basis for the analysis. They clearly show the differences in geometric characteristics. The geometric parameters of the iPhone and iPad are significantly smaller than similar parameters of the Canon. It should be noted that the Canon is not typical of many digital single lens reflex cameras as it has what is often termed a 'full frame sensor' where the sensor format is comparable with the traditional $35 \mathrm{~mm}$ negative $(24 \times 36 \mathrm{~mm})$. The image measurement precision in terms of pixels shows the Canon with the smallest overall RMS followed by the iPhone then the iPad.

Figure 3 shows graphically the radial lens distortion for the three cameras over the range of the iPhone sensor and clearly shows the significantly smaller radial lens distortion in the Canon. The iPad radial distortion is a little larger than the Canon over its small radial distance. Figure 4 gives the radial distortion over the maximum radial distance for the Canon.

Having calibrated the camera it could be argued that these values can be applied regardless of their magnitude however, rapid changes in distortion do increase their sensitivity to the quality of the measured radial distance (image coordinates). 


\subsection{D model building}

\subsubsection{Test site - image capture}

Images from the cameras were taken all round the NGB. The geometry of the cameras created a similar field of view for each camera as can be seen from the building to camera position distance in figures 5, 6, 7 and coverage in figures 8,9 and 10.

Figures 8, 9 and 10 show a similar image of the building taken with the three cameras so that you can see a comparison of images format, coverage and quality. It should be noted that the front of the building was the main focussing plane, so the inserts may not be fully in focus. However, the difference in image quality can be clearly seen from the inserts.
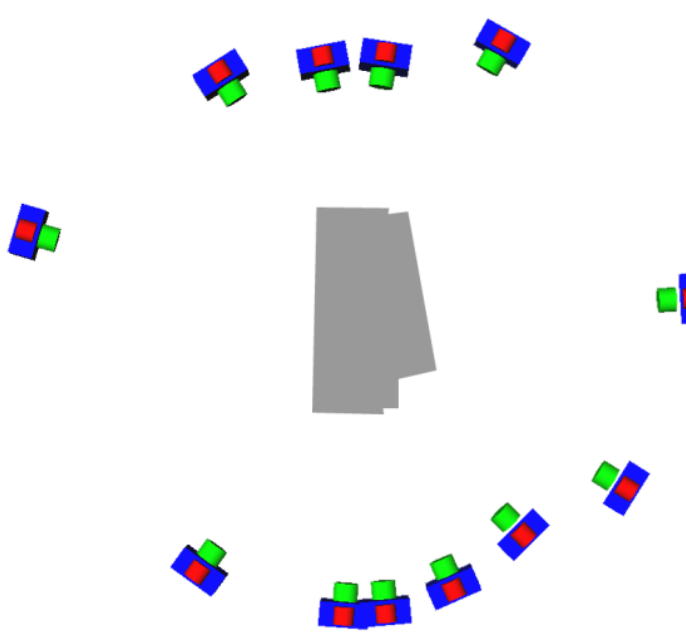

Figure 5. Canon EOS 5D Mk II network of images for 3D building modelling
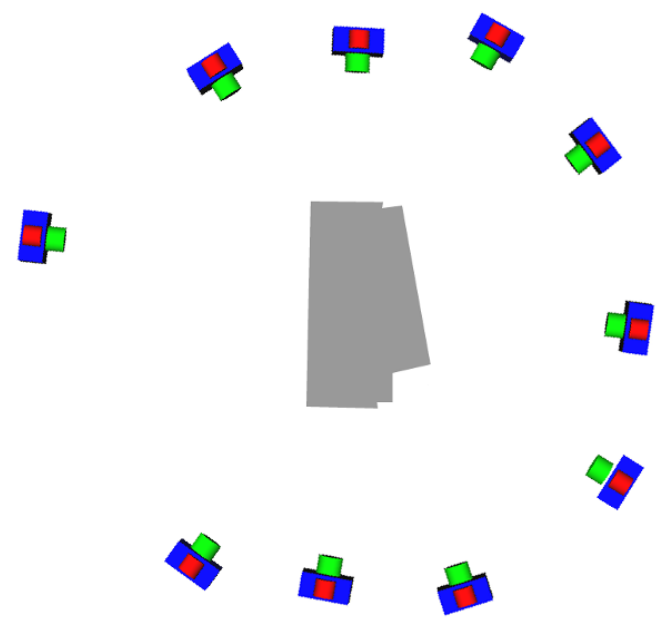

Figure 6. iPhone $4 \mathrm{G}$ network of images used for 3D building modelling

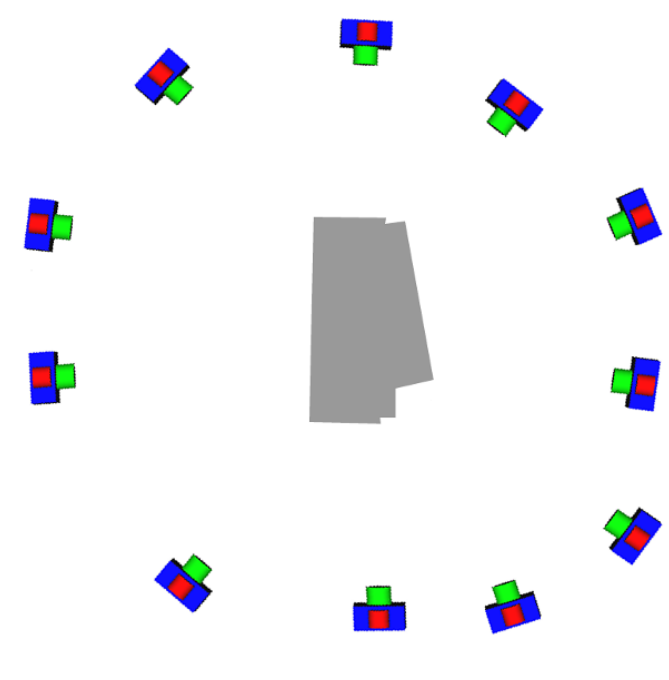

Figure 7. iPad 2 network of images used for 3D building modelling

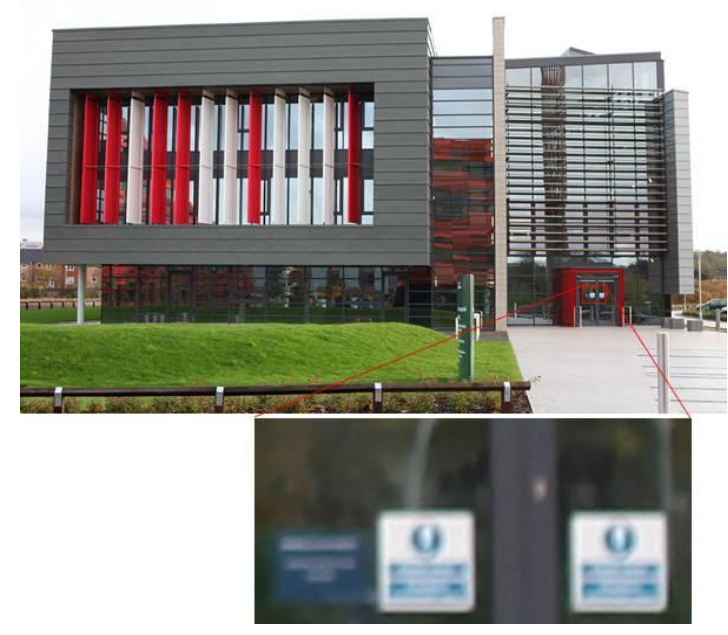

Figure 8, Building facade and image quality from the Canon EOS 5D Mk II

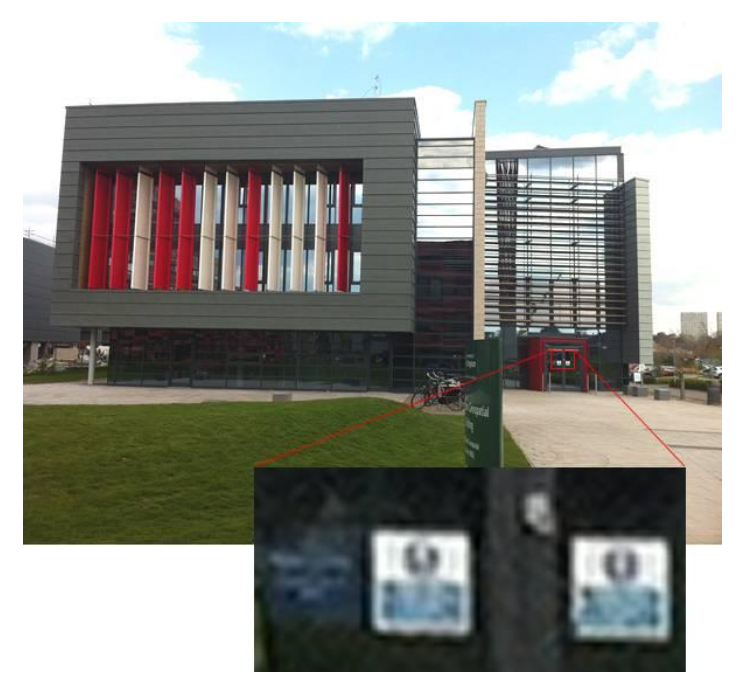

Figure 9. Building facade and image quality from the iPhone 4G 


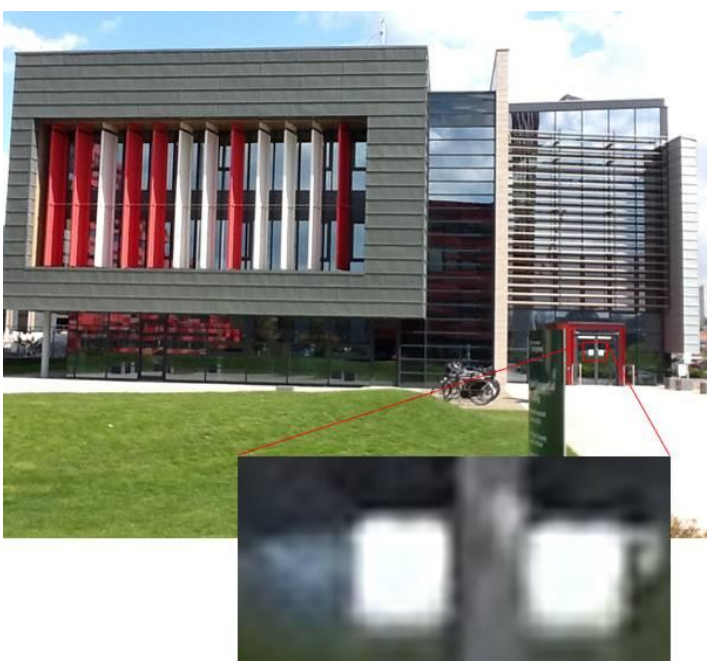

Figure 10. Building facade and image quality from the iPad 2

\subsubsection{Creating the 3D model of the building}

The generation of the $3 \mathrm{D}$ building models from the three different camera sensors was performed using PhotoModeler software. The close range photogrammetric process involved the manual measurement of tie points between the network of overlapping images as shown in figure 11 in order to solve the bundle block adjustment.
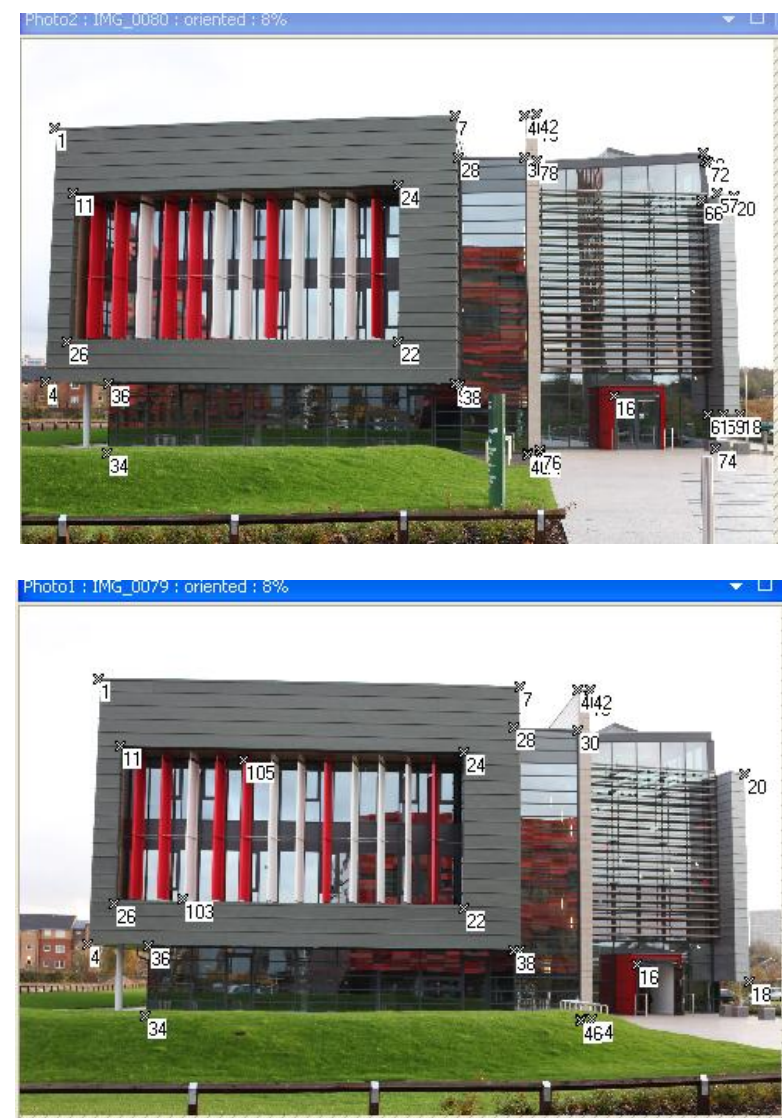

Figure 11. Two overlapping images from Canon EOS 5D Mk II with tie points measured in PhotoModeler

With the bundle block adjustment performed the 3D building model is built by identifying points on the images that represent corners of 3D planes. Each plane is formed by at least $43 \mathrm{D}$ corner points as shown in figure 12. Figure 13 shows the 3D building model created from the Canon images.

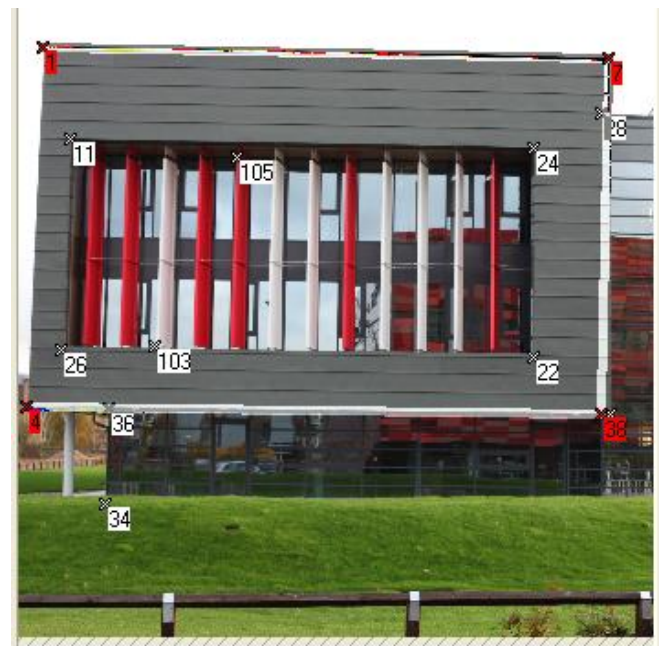

Figure 12. Creating 3D planes of the facades given the corner points
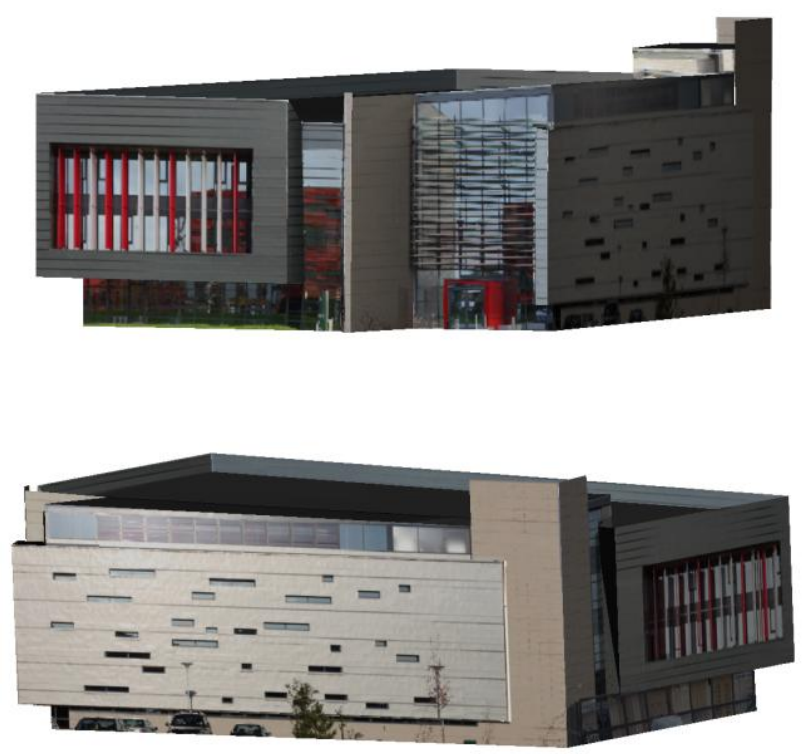

Figure 13. Two perspective views of the $3 \mathrm{~d}$ building model created from the Canon EOS 5D Mk II images

The quality of the position of the points forming the 3D planes of the model was affected by the radiometric quality and resolution of the imagery. Images from Canon were the easiest to work with given the high resolution and exceptional radiometric quality. Identifying and measuring 3D points from the iPhone imagery was slightly more difficult and the iPad images were the most challenging as the quality and resolution of the photos was significantly less.

\subsubsection{Comparison of the 3D building models}

The comparison of the 3D models created was undertaken using Geomagic Studio by performing a 3D volumetric comparison between a reference and a test model. The 3D building model from the Canon was considered the most appropriate to be used 
as a reference and 5 control points were chosen to perform a 3D transformation to fit the iPhone and iPad models to it. Figure 14 shows the 3D difference map between the Canon and the iPhone building models. The deviation between the models was calculated as:

Maximum difference: $+0.030 \mathrm{~m}$

Minimum difference: $-0.024 \mathrm{~m}$

Average: $0.003 \mathrm{~m}$

Standard deviation: $0.004 \mathrm{~m}$

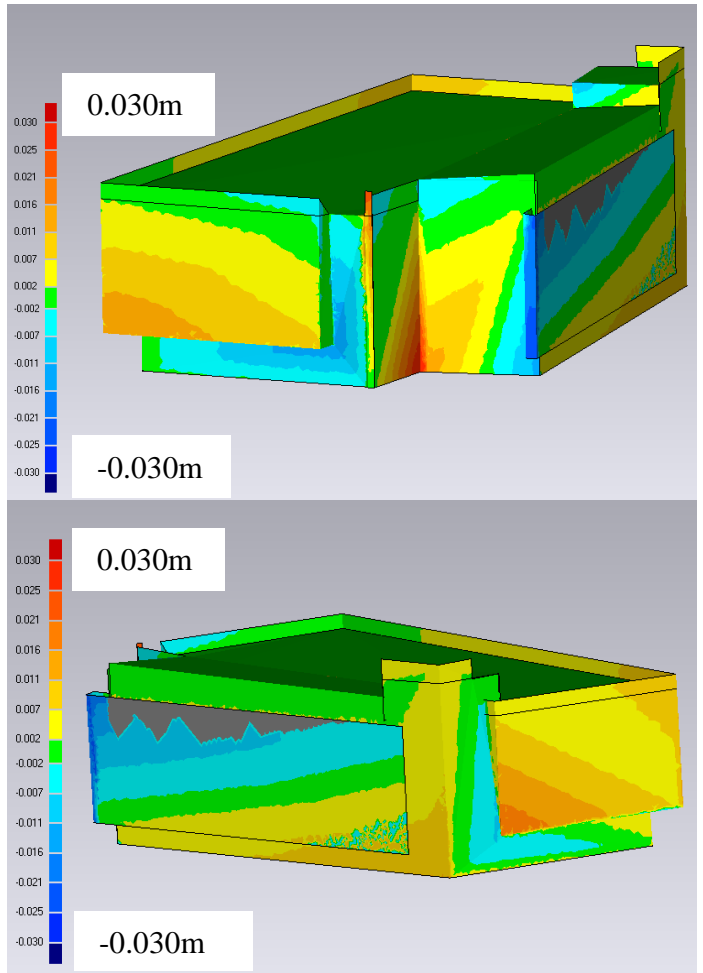

Figure 14. 3D difference map of the front (top) and the back (bottom) facade between the Canon and the iPhone 3D model

The comparison indicates the presence of relatively small differences with the maximum being only $3 \mathrm{~cm}$. This is mainly caused by small differences in the $3 \mathrm{D}$ coordinates of corner points that form the $3 \mathrm{D}$ planes. Some systematic patterns can be seen.

Figure 15 shows the 3D difference map between the Canon and the iPad building models. The deviation between the models was calculated as:

Maximum difference: $+0.080 \mathrm{~m}$

Minimum difference: $-0.057 \mathrm{~m}$

Average: $0.015 \mathrm{~m}$

Standard deviation: $0.017 \mathrm{~m}$

The building model from the iPad 2 presents larger deviations than the iPhone model with a maximum of $8 \mathrm{~cm}$. The reduced quality of the imagery has clearly contributed in the increased differences observed on the front and back facade of the building. Some systematic patterns can be seen.

\section{CONCLUSIONS AND FUTURE ACTIVITIES}

The results above have shown that even with the small lens and sensors the iPhone and iPad have photogrammetric potential.
The calibration of the cameras has shown that over the format of the iPad and iPhone sensor the Canon EOS 5D Mk II has significantly smaller radial lens distortion. Over the small format of the iPad the iPhone has slightly greater radial lens distortion.

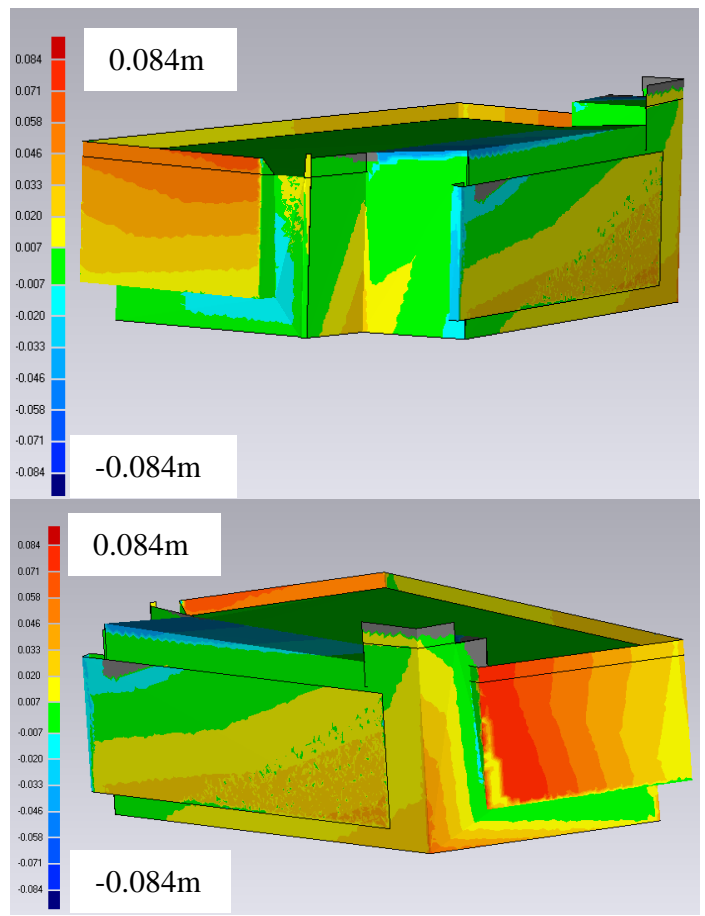

Figure 15. 3D difference map of the front (top) and the back (bottom) facade between the Canon and the iPad 3D model

Both the iPhone and the iPad have produced good quality 3D building models when compared with the Canon model. The iPhone with its larger image format and higher resolution enables better measurements to be made than on the iPad images. Further investigations into the systematic patterns and a wider number of applications will be undertaken.

\section{REFERENCES}

\section{References from Other Literature:}

PhotoModeler, 2012.

PhotoModeler ${ }^{\mathrm{TM}}$ http://www.photomodeler.com/ (accessed 29.03.2012).

Nokia808, 2012. Nokia 808 Pureview specification. http://europe.nokia.com/find-products/devices/nokia-808pureview/specifications (accessed 29.03.2012).

iPad , 2012. iPad 2 Technical Specifications. http://www.apple.com/uk/ipad/ipad-2/specs.html (accessed 15.04.2012)

iPhone, 2012. iPhone Technical Specifications. http://www.apple.com/uk/iphone/specs.html (accessed 15.04.2012)

Canon, 2012.Canon EOS 5D Mk II Technical Specification. http://www.canon.co.uk/For_Home/Product_Finder/Cameras/D igital_SLR/EOS_5D_Mark_II/index.aspx?specs=1 (accessed 15.04.2012) 